\title{
MEASUREMENTS OF COMMON ILIAC ARTERIAL BLOOD FLOW IN ANURANS USING DOPPLER ULTRASOUND
}

\author{
Scott Willens, D.V.M., Ph.D., Sloan H. Dupree, D.V.M., Michael K. Stoskopf, D.V.M., Ph.D., Dipl. \\ A.C.Z.M., Gregory A. Lewbart, D.V.M., M.S., Dipl. A.C.Z.M.
}

\begin{abstract}
Color Doppler ultrasonography was used to determine time-average mean velocity and cross-sectional area of the common iliac artery in bullfrogs (Rana catesbeiana) and marine toads (Bufo marinus). Volumetric blood flow and weight-adjusted blood flow measurements were calculated from this data. Volumetric flow rates of frogs (31.8 $\mathrm{ml} / \mathrm{min}$ ) and toads $(23.6 \mathrm{ml} / \mathrm{min}$ ) did not differ statistically. However, when flow rates were adjusted for body mass, toads displayed a significantly greater flow rate of $238.1 \mathrm{ml} / \mathrm{min} / \mathrm{kg}$ compared to $114.4 \mathrm{ml} / \mathrm{min} / \mathrm{kg}$ for frogs.

Key words: Bullfrog, blood flow, Bufo marinus, Doppler ultrasound, marine toad, Rana catesbeiana.
\end{abstract}

\section{INTRODUCTION}

Cutaneous absorption of xenobiotics is considered a potentially important route of environmental exposure in amphibians, and blood flow is an important factor in the cutaneous absorption kinetics of xenobiotics. ${ }^{1,3,9,14,15,19,20}$ To characterize cutaneous absorption of xenobiotics, in vitro models, such as the two-compartment Teflon flow-through diffusion cell, allow careful control of key environmental variables including temperature, humidity, and $\mathrm{pH} .{ }^{22}$ They can also minimize use of live animals in experiments. Diffusion cells provide a morphologically complete and intact skin barrier and eliminates confounding factors in the analysis of in vivo cutaneous absorption, including absorption, metabolism, or elimination by other routes. Though diffusion cell assays are simple to perform using anuran (frogs and toads) skin, they cannot account for potential effects of variation in blood flow on xenobiotic transport. ${ }^{22}$

Knowledge of the range of arterial flow dynamics in anurans is important for the development of appropriate experimental systems to study cutaneous absorption of vasoactive compounds. Diagnostic ultrasound is a well-established imaging modality in mammalian medicine, but its application in amphibians has been relatively limited. EchoDoppler ultrasonography has successfully been used to study cardiac structure and kinetics, and to measure blood-flow velocity of the heart and great vessels of lower vertebrates, including the common toad (Bufo bufo), and experimentally, pulsed ultra-

From the College of Veterinary Medicine, North Carolina State University, 4700 Hillsborough St., Raleigh, North Carolina 27606, USA. Present address (Willens): USAMRICD, 3100 Ricketts Point Road, Aberdeen Proving Ground, Maryland 21010-5400, USA. Correspondence should be directed to Scott Willens. sound has been used to determine the retardant effects of ultrasound on regeneration of amputated forelimbs of adult newts (Triturus sp) ${ }^{2,12}$ The objective of this study was to establish normal values for blood flow in vessels responsible for the perfusion of the pelvic limb of anurans. This was a first step in developing a system to investigate the pharmacokinetics of environmentally important xenobiotic compounds.

\section{MATERIALS AND METHODS}

\section{Husbandry}

Five wild-caught bullfrogs (Rana catesbeiana), median weight $278 \mathrm{~g}$, and five wild caught marine toads (Bufo marinus), median weight $99 \mathrm{~g}$, were obtained from commercial sources and acclimated to laboratory holding conditions for at least $3 \mathrm{wk}$ before evaluation in these studies. Animals were group housed by species in $61 \mathrm{~cm} \times 61 \mathrm{~cm} \times 46$ $\mathrm{cm}$ deep polyethylene tanks. Bullfrog vivariums were maintained at a $30^{\circ}$ angle to create terrestrial, shallow-water, and deep-water areas. Marine toad vivariums consisted of a terrestrial component with a water bowl. Water and air temperatures were maintained at $21^{\circ} \mathrm{C}$. Fluorescent overhead lighting followed a 12-hr light and 12-hr dark cycle. Complete water changes were conducted every other day with water filtered through activated carbon. Animals were fed to satiety daily with crickets that were allowed to engorge on rodent chow prior to being offered to the amphibians.

\section{Doppler ultrasonography}

Handlers wearing latex-free, powder-free gloves premoistened with filtered water restrained animals in dorsal recumbency on a water-moistened cloth towel for examination. Water-soluble contrast gel (Aquasonic 100 Ultrasound Transmission Gel, Parker Laboratories, Inc., Orange, New Jersey 
Table 1. Common iliac arterial values of bullfrogs and marine toads determined by color Doppler ultrasonography. Values are shown for left and right pelvic limbs of 5 individuals of each species. Median (10-90th percentile) are given for left, right, and overall values for each species.

\begin{tabular}{|c|c|c|c|c|c|c|}
\hline Animal & Mass (g) & TAM $(\mathrm{cm} / \mathrm{sec})$ & Radius (mm) & Area $\left(\mathrm{cm}^{2}\right)$ & $\begin{array}{c}\text { Volumetric } \\
\text { flow }(\mathrm{ml} / \mathrm{min})\end{array}$ & $\mathrm{ml} / \mathrm{min} \cdot \mathrm{kg}$ \\
\hline Frog1Left & 278 & 5.2 & 1.4 & 0.059 & 18.2 & 65.5 \\
\hline Frog1Right & 278 & 7.9 & 1.2 & 0.045 & 21.4 & 76.8 \\
\hline Frog2Left & 358 & 7.0 & 1.6 & 0.079 & 32.9 & 91.9 \\
\hline Frog2Right & 358 & 7.1 & 1.6 & 0.077 & 33.0 & 92.2 \\
\hline Frog3Left & 278 & 8.3 & 1.2 & 0.043 & 21.2 & 76.4 \\
\hline Frog3Right & 278 & 9.1 & 1.1 & 0.039 & 21.3 & 76.7 \\
\hline Frog4Left & 263 & 10.8 & 1.4 & 0.062 & 40.0 & 152.2 \\
\hline Frog4Right & 263 & 8.0 & 1.6 & 0.077 & 37.0 & 140.8 \\
\hline Frog5Left & 240 & 3.7 & 1.1 & 0.038 & 8.4 & 35.2 \\
\hline Frog5Right & 240 & 6.7 & 1.0 & 0.034 & 13.5 & 56.4 \\
\hline FrogLeft & 278 & $7.3(4.5-11.4)$ & $1.6(1.1-1.8)$ & $0.080(0.038-0.102)$ & 35.2 & 126.7 \\
\hline FrogRight & 278 & $8.0(6.7-8.7)$ & $1.5(1.2-1.8)$ & $0.071(0.045-0.102)$ & 33.9 & 122.0 \\
\hline Frogs & 278 & $7.5(4.7-11.1)$ & $1.5(1.1-1.9)$ & $.071(0.038-0.113)$ & 31.8 & 114.4 \\
\hline Toad1Left & 88 & 9.8 & 1.2 & 0.043 & 25.1 & 284.9 \\
\hline Toad1Right & 88 & 7.1 & 1.1 & 0.040 & 17.2 & 195.2 \\
\hline Toad2Left & 119 & 10.6 & 1.0 & 0.033 & 20.7 & 173.7 \\
\hline Toad2Right & 119 & 4.0 & 1.1 & 0.036 & 8.6 & 72.1 \\
\hline Toad3Left & 114 & 5.4 & 1.1 & 0.040 & 13.1 & 114.6 \\
\hline Toad3Right & 114 & 4.2 & 1.1 & 0.040 & 10.2 & 89.9 \\
\hline Toad4Left & 94 & 9.6 & 1.4 & 0.059 & 33.8 & 359.7 \\
\hline Toad4Right & 94 & 8.7 & 1.5 & 0.069 & 36.2 & 385.2 \\
\hline Toad5Left & 99 & 8.8 & 0.9 & 0.026 & 13.9 & 140.9 \\
\hline Toad5Right & 99 & 6.5 & 1.0 & 0.033 & 12.6 & 127.3 \\
\hline ToadLeft & 99 & $9.4(5.5-11.8)$ & $1.4(1.0-1.6)$ & $0.062(0.031-0.080)$ & 34.7 & 350.8 \\
\hline ToadRight & 99 & $5.8(3.8-8.7)$ & $1.2(1.1-1.5)$ & $0.045(0.038-0.071)$ & 15.7 & 159.0 \\
\hline Toads & 99 & $7.4(3.9-10.4)$ & $1.3(1.1-1.7)$ & $0.053(0.038-0.091)$ & 23.6 & 238.1 \\
\hline
\end{tabular}

07050, USA) was applied bilaterally to the inguinal regions. A color Doppler ultrasound machine (Siemens Allegra, Erlangen, Germany) with a $7.5-\mathrm{MHz}$ linear transducer (Siemens Allegra) was used to record vascular dimensions. The transducer was gently applied over the pulsing common iliac artery just proximal to its bifurcation. Measurements were taken at times when animals were not breath holding. This minimized the potential impact of increased intracoelomic pressure due to pulmonary distension on arterial diameter. Although animals were respiring freely, three successive measurements of maximum and minimum elliptical diameter were obtained while imaging in a transverse plane to the vessel at times when the common iliac artery appeared most nearly circular by visual inspection. The minimum elliptical radius was used to calculate vessel cross-sectional area. This was followed by three successive time-averaged mean velocity measurements (TAM) taken in a longitudinal plane to the vessel.

Volumetric flow rate $(\mathrm{ml} / \mathrm{min})$ for each animal was calculated from the product of the TAM in $\mathrm{cm} /$ sec and the cross-sectional area of the artery $\left(\mathrm{cm}^{2}\right)$ multiplied by $60 .{ }^{10,13}$ Flow rate per kilogram body weight was then calculated. A Wilcoxon signed ranks test was used for nonparametric statistical comparison between left and right pelvic limb data and between frog and toad data considering a $p$ value $<0.05$ as significant.

\section{RESULTS}

No significant differences $(p<0.05)$ were noted between left and right common iliac arterial radii, TAM values, or resulting volumetric flow rates for frogs (Table 1). No statistically significant differences were seen between left and right common iliac arterial radii for toads. However, median (10th-90th percentile) TAM values did differ significantly $(p=0.03)$ with velocity of left common iliac arteries $(9.4(5.5-11.8) \mathrm{cm} / \mathrm{sec})$ greater than the right $(5.8[3.8-8.7] \mathrm{cm} / \mathrm{sec})$.

Time-averaged mean velocities did not differ between frogs and toads, and the median TAMs (10th-90th percentile) were $7.5 \mathrm{~cm} / \mathrm{sec}(4.7-11.1$ $\mathrm{cm} / \mathrm{sec})$ and $7.4 \mathrm{~cm} / \mathrm{sec}(3.9-10.4 \mathrm{~cm} / \mathrm{sec})$, respec- 
tively. The median radius of the common iliac artery did not differ between frogs and toads, with values of $1.5 \mathrm{~mm}(1.1-1.9 \mathrm{~mm})$ and $1.3 \mathrm{~mm}(1.1-$ $1.7 \mathrm{~mm})$, respectively. Volumetric flow rates of frogs $(31.8 \mathrm{ml} / \mathrm{min})$ and toads $(23.6 \mathrm{ml} / \mathrm{min}) \mathrm{did}$ not differ statistically $(p>0.05)$. However, when flow rates were adjusted for body mass, toads displayed a significantly greater median flow rate $(p<0.05)$ of $238.1 \mathrm{ml} / \mathrm{min} / \mathrm{kg}$ compared to $114.4 \mathrm{ml} / \mathrm{min} / \mathrm{kg}$ for frogs.

\section{DISCUSSION}

Common iliac volumetric blood flow rates were comparable in bullfrogs and marine toads. Therefore, blood flow is not likely to be a source of differential cutaneous absorption between these species. This makes it convenient to set common perfusion rates for in vitro experiments, such as twocompartment Teflon flow-through diffusion cells. ${ }^{22}$ No significant differences were noted in the percutaneous absorption kinetics of malathion in bullfrogs and marine toads using a flow rate of $1 \mathrm{ml} /$ min. ${ }^{22}$ Anuran tissue perfused by arterial cannulation would also need to rely on a physiologically accurate perfusion rate. A flow rate of $1 \mathrm{ml} / \mathrm{min}$ is sufficient to maintain patency of the common iliac artery of anurans. ${ }^{21}$ However, the results of this study show that $1 \mathrm{ml} / \mathrm{min}$ may not be a physiologically relevant perfusion rate.

The values obtained for volumetric flow in both species were high in comparison to mammals. ${ }^{10,13}$ Comparable results for systemic and pulmocutaneous blood flow have been reported in $R$. catesbeiana and $B$. marinus using other diagnostic methods. ${ }^{4,11}$ Pulmocutaneous arterial blood flow (24.5 $\mathrm{ml} / \mathrm{min}$ ) has been described in anesthetized $R$. catesbeiana (compared to common iliac arterial blood flow of $31.8 \mathrm{ml} / \mathrm{min}$ in our study). ${ }^{11}$ Another study measured systemic $(77.2 \mathrm{ml} / \mathrm{min} / \mathrm{kg}$ ) and pulmocutaneous arterial blood flow $(26.2 \mathrm{ml} / \mathrm{min} / \mathrm{kg})$ in B. marinus at $25^{\circ} \mathrm{C}$ (compared to common iliac arterial blood flow of $238.1 \mathrm{ml} / \mathrm{min} / \mathrm{kg}$ in our study). ${ }^{4}$ The values obtained in our study could also be explained by apparent resistance to manual restraint. Stress and strenuous exercise may increase the metabolic rate by as much as nine times that of resting amphibians. ${ }^{5}$ Higher volumetric flow rates in toads could be explained by persistent struggling. One study demonstrated that $B$. marinus has greater maximal (exercised) blood flow rates due to higher heart rates, increased pulse volumes and lower peripheral resistance than $R$. catesbeiana, although the toads in their study were only $60 \%$ as large as the bullfrogs. ${ }^{8}$

In addition, breath holding in toads could not be completely prevented during the study. Measurements obtained between episodes of breath holding likely reflect a rebound increase in peripheral blood flow due to a concurrent decrease intracoelomic pressure. In future studies, this effect could be reduced by eliminating manual restraint. Aquatic and semiaquatic amphibians, such as bullfrogs, can be placed in a water-filled container and ultrasonography performed across the barrier. ${ }^{18}$ Use of an anesthetic, such as tricaine methanosulfonate, is another alternative to manual restraint. Though these techniques have not been used traditionally for amphibians, they provide the promise to improve the health management of amphibians. Ultrasound could be used for detecting vascular perfusion changes in common diseases, such as bacterial septicemias and mycotic dermatitis, as a possible adjunct in establishing prognosis for valuable specimens.

Manual restraint and design of the data-collection sequence could explain the higher TAM values for left versus right common iliac arteries in toads. Left-sided values were always obtained first followed by evaluation of the right common iliac artery. It is possible that animals accommodated to being held over time and had reduced cardiac rate and output.

Study design, level of activity, species physiology, and human error (variation in angle of the transducer in relation to blood flow) are sources of variability. Even small permutations in arterial radius $(r)$ and errors in measurement have a large effect on cross-sectional area $\left(\pi r^{2}\right)$ and resultant volumetric flow calculations because of an incremental increase in radius resulting in a second power increase in area.

Sustained flow rates of $25-30 \mathrm{ml} / \mathrm{min}$ could create a high perfusion pressure and subsequent extravasation of the perfusate. ${ }^{17}$ Isolated pelvic limb perfusions of nude rats are conducted with the use of a flow rate of $4 \mathrm{ml} / \mathrm{min} \cdot{ }^{23}$ Capillary filtration rates and coefficients in $R$. catesbeiana and B. marinus are considerably greater than those found in mammals, predisposing them to plasma and lymphatic fluid shifts at high flow volumes. ${ }^{6}$ Anurans are able to compensate for fluid flux between the vascular and lymphatic compartments and prevent tissue damage. ${ }^{7}$ A pressure gradient created by compartmentalization of hind-limb lymph spaces into sacs is assisted by skeletal muscle contractions to move lymph cranially. ${ }^{\text {? }}$

Flow rates of $25 \mathrm{ml} / \mathrm{min}$ are logistically difficult to achieve in vitro considering the constraints of most peristaltic pumps. A perfusion rate of $1 \mathrm{ml} /$ min would conform to peristaltic pump capabilities 
while maintaining vessel patency and preventing extravasation of perfusate fluid. This rate also corresponds to the perfusion rate used in isolated perfused porcine skin flaps used to model absorption by human skin. ${ }^{16}$ The perfusion rate of subsequent anuran in vitro perfusion studies should be dependent on the objective of the study. If the goal is to standardize technique with that of existing mammalian protocols, then a flow rate of $1 \mathrm{ml} / \mathrm{min}$ is appropriate, with the understanding that the rate does not approximate physiological blood flow in anurans. ${ }^{21}$ However, if the objective is to achieve physiologically relevant pharmacokinetic data for amphibians, higher flow rates should be employed. It is important to determine normal blood flow because vascular perfusion directly impacts the percutaneous absorption of pharmaceuticals and toxins. Extravasation and lymphatic drainage of perfusate have potential implications on recovery and partitioning effects of xenobiotics, and models working with amphibians should take these factors into account when establishing perfusion flow rates. $^{21}$

Acknowledgments: This study was supported by Grant No. R-82968201 from the United States Environmental Protection Agency's National Center for Environmental Assessment, Research Triangle Park, North Carolina. We thank Lab Animal Resources at the College of Veterinary Medicine, North Carolina State University, for animal care and husbandry. The experiments comply with the current laws of the United States of America and with the guidelines of the Institutional Animal Care and Use Committee of North Carolina State University.

\section{LITERATURE CITED}

1. Boutsiouki, P., J. P. Thompson, and G. F. Clough. 2001. Effects of local blood flow on the Percutaneous absorption of the organophosphorous compound malathion: a microdialysis study in man. Arch. Toxicol. 75: 321-328.

2. Coucelo, J., J. Coucelo, and J. Azevado. 1996. U1trasonography characterization of heart morphology and blood flow of lower vertebrates. J. Exp. Zool. 275: 7382.

3. Fordham, C. L., J. D. Tessari, H. S. Ramsdell, and T. J. Keefe. 2001. Effects of malathion on survival, growth, development, and equilibrium posture of bullfrog tadpoles (Rana catesbeiana). Environ. Toxicol. Chem. 20: 179-184.

4. Gamperl, A. K., W. K. Milsom, A. P. Farrell, and T. Wang. 1999. Cardiorespiratory responses of the toad (Bufo marinus) to hypoxia at two different temperatures. J. Exp. Biol. 202: 3647-3658.

5. Gatten, R. E., Jr., K. Miller, and R. J. Full. 1992. Energetics at rest and during locomotion. In: Feder, M.
E., and W. W. Burggren (eds.). Environmental Physiology of the Amphibians. University of Chicago Press, Chicago, Illinois. Pp. 314-377.

6. Hancock, T. V., T. M. Hoagland, and S. S. Hillman. 2000. Whole-body systemic transcapillary filtration rates, coefficients, and isogravimetric capillary pressures in Bufo marinus and Rana catesbeiana. Physiol. Biochem. Zool. 73: $161-168$.

7. Hillman, S. S., M. S. Hedrick, P. C. Withers, and R. C. Drewes. 2004. Lymph pools in the basement, sump pumps in the attic: the anuran dilemma for lymph movement. Physiol. Biochem. Zool. 77: 161-173.

8. Hillman, S. S., and P. C. Withers. 1977. The hemodynamic consequences of hemorrhage and hypernatremia in two amphibians. Comp. Physiol. B. 157: 807-812.

9. Johnson, M. S., S. D. Holladay, K. S. Lippenholz, J. L. Jenkins, and W. C. McCain. 2000. Effects of 2,4,6trinitrotoluene in a holistic environmental exposure regime on a terrestrial salamander, Ambysoma tigrinum. Toxicol. Pathol. 28: 334-341.

10. Kantrowitz, B. M., T. G. Nyland, and P. Fisher. 1989. Estimation of portal blood flow using duplex realtime and pulsed Doppler ultrasound imaging in the dog. Vet. Radiol. 30: 222-226.

11. Nagai, M., and M. Iriki. 1986. Characteristics of cardiovascular responses of the bullfrog (Rana catesbeiana) to thermal stimulation of the spinal cord. J. Comp. Physiol B 156: 611-616.

12. Pizzarello, D. J., A. Wolsky, M. H. Becker, and A. F. Keegan. 1975. A new approach to testing the effect of ultrasound on tissue growth and differentiation. Oncology 31: 226-232.

13. Raisis, A. L., L. E. Young, H. B. Meire, P. M. Taylor, K. J. Blissitt, D. Marlin, and P. Lekeux. 2000. Measurements of hindlimb blood flow recorded using Doppler ultrasound during administration of vasoactive agents in halothane-anesthetized horses. Vet. Radiol. Ultrasound. 41: 42-72.

14. Relyea, R. A. 2004. Synergistic impacts of malathion and predatory stress on six species of North American tadpoles. Environ. Toxicol. Chem. 23: 1080-1084.

15. Riviere, J. E. 1999. Comparative Pharmacokinetics. Iowa State University Press, Ames, Iowa.

16. Riviere, J. E., N. A. Monteiro-Riviere, and A. O. Inman. 1997. The effect of altered media flow and glucose concentration on sulfur mustard toxicity in the isolate perfused porcine skin flap. In Vitro Toxicol. 10: 169-181.

17. Sanchez-del-Rio, M., and U. Reuter. 2004. Migraine aura: new information on underlying mechanisms. Curr. Opin. Neurol. 17: 289-293.

18. Stetter, M. D. 2001. Diagnostic imaging of amphibians. In: Wright, K. M., and B. R. Whitaker (eds.). Amphibian medicine and captive husbandry. Krieger, Malabar, Florida. Pp. 253-272.

19. Talbot, R. 2002. The effects of perfusion on the cutaneous vasculature on sodium uptake across isolated frog skin. J. Comp. Physiol. 172: 209-216.

20. Taylor, S. K., E. S. Williams, and K. W. Mills. 1999. Effects of malathion on disease susceptibility in Woodhouse's toads. J. Wildl. Dis. 35: 536-541. 
21. Willens, S., S. H. Dupree, M. K. Stoskopf, G. A. Lewbart, S. K. Kennedy-Stoskopf, and S. K. Taylor. 2004a. Measurements of common iliac arterial blood flow in bullfrogs (Rana catesbeiana) and marine toad (Bufo marinus) using Doppler ultrasound. Proc. Int. Assoc. Aquat. Anim. Med. Pp. 43-44.

22. Willens, S., M. K. Stoskopf, R. E. Baynes, G. A. Lewbart, S. Kennedy-Stoskopf, and S. K. Taylor. 2004b. Use of two-compartment Teflon flow-through diffusion cells to study cutaneous absorption kinetics of malathion in the bullfrog (Rana catesbeiana) and marine toad (Bufo marinus). Proc. Int. Assoc. Aquat. Anim. Med. Pp. 4556.

23. Wu, Z., M. S. Roberts, P. G. Parsons, and B. M. Smithers. 1997. Isolated limb perfusion with malphalan for human melanoma xenografts in the hindlimb of nude rats: a surviving animal model. Melanoma Res. 7: 19-26.

Received for publication 9 February 2005 